\title{
O impacto das reformas econômicas neoliberais na América Latina: desemprego e pobreza
}

\author{
Rosana Soares Campos \\ Universidade Federal de Santa Maria, Santa Maria, Brasil. \\ Email: rosanascampos@yahoo.com.br
}

\begin{abstract}
Resumo $^{1}$ : O objetivo deste artigo é analisar a aguda realidade produzida e reproduzida pelas políticas econômicas neoliberais, na década de 1990, na América Latina, a partir de duas de suas mais graves consequências: o desemprego e a pobreza e suas relações com as reformas econômicas. O desemprego é discutido através das transformações do mercado de trabalho nos anos 1990. E a pobreza é observada pela intensidade e extensidade do fenômeno. Nesse sentido, as duas categorias, trabalho e pobreza, são examinadas sob as perspectivas teórica e histórica e em um segundo momento verifica-se através da análise estatística do modelo de regressão a causalidade entre as variáveis desemprego e pobreza com as reformas. Os resultados confirmam a relação e mostram a influência das reformas econômicas no aumento do desemprego e da pobreza na América Latina, durante o decênio de 1990.
\end{abstract}

Palavras-chave: América Latina, trabalho, pobreza, neoliberalismo

\section{El impacto de las reformas económicas neoliberales en América Latina: desempleo y pobreza}

Resumen: El propósito de este artículo es analizar la realidad aguda producida y reproducida por las políticas económicas neoliberales en la década de 1990 en América Latina, a partir de dos de sus más graves consecuencias: el desempleo y la pobreza y su relación con las reformas económicas. El desempleo se discute a través de los cambios en el mercado laboral. Y la pobreza se observa por la intensidad y el alcance del fenómeno. En consecuencia las dos categorías, el trabajo y la pobreza, se analizan primero desde las perspectivas teóricas e históricas y en un segundo momento, en que aparece a través del análisis estadístico del modelo de regresión la causalidad entre las variables desempleo y pobreza con las reformas. Los resultados confirman la relación y muestran la influencia de las reformas económicas en el aumento del desempleo y de la pobreza en América Latina durante la década de 1990.

Palabras clave: América Latina, trabajo, pobreza, neoliberalismo

\section{The impact of neoliberal economic reforms in Latin America: unemployment and poverty}

\footnotetext{
Abstract: The aim of this paper is to analyze the acute reality produced and reproduced by the neoliberal economic policies in the 1990s in Latin America,
} 
from two of its most serious consequences: unemployment and poverty and its relationship with economic reforms. Unemployment is discussed through the changes in the labor market in the 1990s. And the poverty is observed by the intensity and extent of the phenomenon. The two categories, work and poverty, are examined from the theoretical and historical perspectives. In a second step it is verified, through the analysis of the regression model the causality between variables unemployment and poverty with reforms. The results confirm the relationship and show the influence of economic reforms in the rising unemployment and poverty in Latin America during the 1990 decade.

Keywords: Latin America, labor, poverty, neoliberalism

$$
* * *
$$

\section{Introdução}

A década de 1990 na América Latina, com seus recém (re)estabelecidos regimes democráticos, foi marcada pela implementação e consolidação de políticas econômicas neoliberais ${ }^{2}$. Essas políticas foram justificadas como mecanismo de combate à crise econômica dos anos 1980. Argumenta-se que essas reformas causaram, entre outras consequências, o aumento do desemprego/subemprego e da pobreza na região; que se visibilizaram pela extensão e intensidade. Nesta perspectiva, o objetivo desse estudo é verificar, através de estatísticas descritiva e inferencial, pelo modelo de regressão, a relação entre a implementação de reformas econômicas e o aumento do desemprego e da pobreza no decênio de 1990 na América Latina, observando a força, a significância e o quanto o aumento das reformas impactou no crescimento de desempregados e pobres na região.

\section{As bases teóricas: trabalho e pobreza}

A pesquisa fundamenta-se em duas categorias analíticas: trabalho e pobreza. No que se refere ao trabalho, a discussão perpassa pelo debate acerca de suas transformações no final do século XX. Nesta perspectiva, Robert Castel (1998) chama a atenção para a ameaça de fratura social ocasionada pelo processo de globalização e pelas políticas econômicas neoliberais, através de uma “desmontagem” no sistema de proteções, desestabilizando a sociedade salarial, construída e solidificada no decorrer do século XX. Na sociedade salarial, analisada por Castel (2010), a maioria dos sujeitos sociais tem sua inserção social relacionada ao lugar que ocupa no espaço do trabalho, não se resumindo à renda, mas também seu status, sua proteção e identidade. A fragmentação dessa sociedade, para o referido autor, é a grande questão social na atualidade, porque não é apenas o fim do pleno emprego, é também o aumento da instabilidade do emprego e o reaparecimento de “trabalhadores sem trabalho”. Para Castel (2010), este momento caracteriza-se em três importantes e inquietantes questões sociais: 1) a desestabilização dos estáveis; 2) a instalação da precarização, como 
uma das respostas sociais à exigência de flexibilidade, alternando períodos de atividades, de desemprego, de trabalho temporário, inatividade e ajuda social; e 3) a existência de pessoas que poderiam ser chamadas de sobrantes, que não são integradas na sociedade e talvez também não sejam porque foram invalidadas pela nova conjuntura econômica e social. Nesse cenário, o desemprego, conforme o autor, foi a manifestação mais visível e o risco social mais grave na dinâmica dessas políticas econômicas; pois teve um efeito desestabilizador e dessocializante.

A sociedade salarial de Castel que começou a se fragmentar no final dos anos 1970, com mais intensidade entre as décadas de 1980 e 1990, foi a dos países avançados, com suas proteções e assalariamento universal. Em países em desenvolvimento, como os da América Latina, a perversidade das transformações foi ainda maior, pois se deu numa sociedade frágil, onde ainda não estavam garantidas proteções sociais a todos. Por isso, as políticas neoliberais quando não desempregaram os trabalhadores, precarizaram ainda mais o trabalho.

Numa perspectiva de análise semelhante à de Robert Castel, Ricardo Antunes e Giovanni Alves (2004) observaram que na América Latina o neoliberalismo e a reestruturação produtiva da era da acumulação flexível, dotada de forte caráter destrutivo, acarretou, entre tantos aspectos nefastos, um monumental desemprego e uma enorme precarização do trabalho. De acordo com os autores, "essa lógica do sistema produtor de mercadorias vem convertendo a concorrência e a busca da produtividade num processo destrutivo que tem gerado uma imensa sociedade dos excluídos e dos precarizados”. (Antunes e Alves, 2004, p.36)

Para Antunes e Alves (2004), essas mudanças no capitalismo contemporâneo são de intensa destrutividade, porque eliminam a força humana que trabalha, destroçam os direitos sociais, brutalizam enormes contingentes de homens e mulheres que vivem do trabalho, tornam predatória a relação produção-natureza criando o que Antunes chamou de “monumental sociedade do descartável”. É nesse sentido que, conforme Antunes e Alves, desregulamentação, flexibilização e terceirização são expressões de uma lógica societal onde o capital tem um poder imenso e a força humana de trabalho só conta enquanto parcela para a reprodução deste mesmo capital.

Três movimentos reordenaram o mercado de trabalho neste período estudado. A globalização causou o deslocamento espacial do emprego, a financeirização diminuiu a quantidade de emprego devido ao encolhimento da base produtiva e a reestruturação produtiva acarretou um novo mercado de trabalho - segmentado e precário. Para David Harvey (1992), este novo mercado surgiu como resultado do que ele chamou de acumulação flexível.

O mercado de trabalho informal, que é o espaço histórico do 
trabalho na América Latina, expandiu-se nos anos 1990 como resultado das transformações capitalistas, adequando-se para captar as novas situações do trabalho na região. Conforme as observações de Rogério Silva (2003), o circuito tradicional da informalidade, associado a trabalhadores menos qualificados, com baixas renda e produtividade, esticou-se para comportar os ex-assalariados, expulsos do mercado formal ou jovens recém-ingressos na população economicamente ativa.

Para Maria Cristina Cacciamalli (2000), na dimensão do mercado, o processo de informalidade na América Latina revelou-se por meio da destruição, adaptação e redefinição de um conjunto de instituições, regras e normas envolvendo as relações entre as empresas para organizar a produção e sua distribuição, os processos de produção do trabalho, as formas de inserção no trabalho, as relações de trabalho e os conteúdos dessas ocupações. Ainda, conforme Cacciamalli, estas características provocaram dois fenômenos: 1) a reorganização do trabalho assalariado e consequente aumento da vulnerabilidade nas situações de trabalho e 2) aumento do emprego por conta própria e estratégias de sobrevivência, associadas ao setor informal, geralmente em atividades de baixa produtividade, o que revela uma precarização do trabalho.

Neste contexto de transformações do mundo do trabalho, provocadas pelas políticas econômicas neoliberais, houve um aumento substancial do número de pobres. Nas observações de Sônia Leguizamón (2005), estas políticas representaram uma nova fase da pobreza na América Latina. A autora aponta algumas causas dessa pobreza massiva que acarretaram mudanças no mundo do trabalho: 1) a impossibilidade de gerar ingressos pela via da condição assalariada formal ante o crescente uso do capital intensivo na produção e nos processos de desjurisdição ${ }^{3}$ das relações de trabalho; 2) a reforma do mercado de trabalho, a flexibilização trabalhista, a seguridade social; 3) a impossibilidade de acesso a outros meios de subsistência para gerar meios para a reprodução da vida; 4) a reforma dos regimes de estado de bem-estar e 5) novas formas de discriminação étnico-cultural.

Neste sentido é que Sônia Leguizamón chama a atenção para o fato de que a pobreza deve ser analisada como uma construção social, produto de relações sociais. E, ao mesmo tempo em que é produzida por determinadas relações, também reproduz determinados fenômenos sociais como o desemprego, o subemprego, a precariedade do trabalho e da vida, retroalimentando este círculo vicioso. Partindo da concepção de que a pobreza "[...]é, sobretudo, uma relação entre pessoas, um estado social e, como tal, é um invento da civilização", (Sahlins,1977 apud Gutiérrez, 2007, p. 23), compreende-se que as políticas neoliberais produziram e reproduziram mais pobreza durante a sua implementação na América Latina, na década de 1990.

A pobreza enquanto produção social vai muito além da escassez de renda monetária. Ela abrange múltiplas dimensões e está, 
consequentemente, condicionada ao modo de produção, acumulação e distribuição do capital, dos recursos e de sua escassez. Nesse sentido, pobreza é uma construção. Um fenômeno que ganhou visibilidade nos anos 1990 devido à intensidade e perversidade da situação em que se encontravam milhões de pessoas no mundo inteiro, inclusive na América Latina. Porém é um fenômeno antigo que ganhou novas formas, como o empobrecimento dos que não eram pobres e a recomposição social dos vínculos sociais - fragmentação e segmentação, já abordados nas ideias de Robert Castel.

Em seus estudos sobre produção e reprodução da pobreza, Sônia Leguizamón (2005) argumenta que os fatores econômicos no capitalismo são fundamentais para se entender este fenômeno. Conforme a autora, a tensão entre a lógica do capital, o bem-estar e a dialética dos interesses contraditórios entre o capital e o trabalho explicam grande parte da produção da pobreza massiva. Além desses processos, para Leguizamón, estão também os sistemas discursivos como visões de mundo que naturalizam as relações sociais, econômicas e culturais.

O conceito de pobreza utilizado por Leguizamón refuta a tese liberal de que esta situação faz parte do processo de reestruturação e modernização de uma sociedade. Um conceito que vai de encontro ao modo como os organismos internacionais e os Estados justificam este fenômeno e tentam minimizá-lo controlando-o através de medidas quantitativas, mensuradas pela renda e necessidades mais básicas.

Na década de 1990 a pobreza tornou-se um grande problema, quando ultrapassou as fronteiras do controle social na medida em que as políticas neoliberais foram sendo implementadas. Por esta razão, Estado e organismos internacionais tomaram medidas para conter os mais pobres entre os pobres e camuflar, em números, a situação real das consequências neoliberais. No começo da década de 1990 o Banco Mundial instituiu a linha de pobreza para medir a quantidade de pobres no mundo. Na concepção dessa instituição era pobre quem recebia até dois dólares por dia, e indigente quem se mantinha com um dólar.

Ainda na metade dos anos 1990 essa medida foi criticada e passou a ser complementada pela ideia das necessidades básicas, como alimentação, educação e saúde. E a concepção de necessidades básicas tornou-se um colchão amortecedor para as reformas estruturais que o Banco Mundial e o Fundo Monetário Internacional (FMI) estavam promovendo nos países subdesenvolvidos. (Leguizamón, 2005, p. 251).

A partir da dimensão de necessidades básicas, o Programa das Nações Unidas para o Desenvolvimento (PNUD) lançou também na década de 1990 o conceito de desenvolvimento humano, partindo da concepção de que para medir o desenvolvimento da população se deve considerar além da dimensão econômica, características sociais, culturais e políticas que influenciassem na qualidade de vida dos cidadãos. Desse 
modo, a pobreza passou a ser interpretada multidimensionalmente e, nessa compreensão, os programas focalizados de assistências emergencial e básica aos pobres começaram a entrar em vigor. Dessa forma, organizava-se o sistema discursivo do "desenvolvimento humano”, promovido pelo Banco Mundial. Este organismo internacional, conforme Leguizamón, exime o mercado de qualquer tipo de regulação e ratifica que os que não conseguiram obter sucesso devem então querer e receber apenas ajuda para as necessidades básicas.

Os estudos de Sônia Leguizamón (2005) evidenciam uma postura crítica a essa vertente através de uma análise dos discursos minimalistas de redução da pobreza que, na verdade, reproduzem a desigualdade, e estratificam ainda mais as pessoas. Para Leguizamón, esses discursos minimalistas sobre a redução da pobreza, via desenvolvimento humano, não promovem políticas redistributivas. Baseiam-se no ataque à pobreza através de políticas focalizadas, compensatórias, por meio da provisão de mínimos biológicos para a sobrevivência. Conforme a autora, criouse uma nova arte de governar esse problema, que ela chamou de focopolítica, promovida por organismos internacionais nos anos 1990.

É nessa direção que Majid Rahnema (2005) classifica a pobreza atual de pobreza modernizada, gerada depois da Revolução Industrial, rompendo com as formas prévias do fenômeno, pois se estabelecem necessidades pessoais que os indivíduos têm dificuldades materiais de satisfazê-las. E que, segundo o autor, é uma corrida sem fim, uma situação que torna as pessoas dependentes do mercado e das necessidades que o mesmo segue criando. É nesse sentido que Rahnema afirma que o poder discursivo das grandes instituições reestrutura a vida dos pobres e os despotencializa na medida em que o aparato discursivo do desenvolvimento e suas práticas definem suas vidas pelo que podem ou não consumir.

A pobreza modernizada, categorizada por Rahnema, é o resultado de um sistema discursivo. E é constantemente reproduzida por 'perpetuadores', de acordo com Else Oyen (2002). Ou seja, por pessoas, instituições, situações que direta ou indiretamente contribuem para a manutenção do fenômeno. A identificação desses agentes ganhou importância nos estudos sobre a produção da pobreza, na medida em que se observa que essa produção foi resultado da ação de alguém, de algum grupo ou instituição, ou mesmo desastre natural.

Além disso, a pobreza tem um componente que, se não perpetua o pobre no mundo dos pobres, dificulta a mobilidade social: a exclusão. Ser pobre é estar excluso ou incluso precariamente nas diversas esferas da vida social. E essa exclusão, como aponta Atkinson e Hillo (apud Narayan, 2000), é um processo dinâmico, visto que os indivíduos são excluídos não apenas pela privação de trabalho ou renda, mas também devido à falta de perspectivas de futuro e a preconceitos de cor, etnia, gênero, etc. 
A dinamicidade do processo de exclusão significa estar à margem das formas econômica, política e cultural de inserção na sociedade. Pois a exclusão econômica implica não inserção no mercado de trabalho, dificultando o acesso à propriedade, capital, educação, capacitação profissional. A exclusão política funda-se na dificuldade encontrada pelos segmentos pobres da população em manter uma organização mínima que lhes permita participar da tomada de decisões que afetam as suas condições de vida. E a exclusão cultural é a inexistência, precariedade ou ruptura das relações sociais primárias impedindo a geração ou preservação desses laços (OIT/ PNUD / IIEL apud Arriagada, 2000).

Nesse sentido é que Castells (1999) chama a atenção para o fato de que a perda por estar excluso socialmente é muito mais do que a do rendimento. Ou seja, a perversidade desse processo não se resume apenas à privação de trabalho ou renda. Elimina, marginaliza ou impossibilita a entrada nas formas de participação das várias esferas da sociedade. Porém, é a privação do trabalho ou sua precariedade que primeiro se materializa em exclusão social, desigualdade e pobreza. O comportamento do mercado de trabalho e a extensão e intensidade da pobreza, no decênio de 1990, evidenciam essa dinamicidade da exclusão na região latinoamericana.

\section{Resultados e Discussão}

\section{A estatística descrevendo a realidade: trabalho e pobreza na década de 1990}

Como já apontado por Robert Castel (1998), é o desemprego a manifestação mais visível desse processo de acumulação capitalista do final do século XX, acompanhado por mais duas características do trabalho, a informalização e a precarização. Foi, pois, na década de 1990 que, na América Latina, esta manifestação visibilizou-se com tamanha intensidade, sendo acompanhada pela expansão do setor informal e da baixa qualidade do trabalho. Para Maria Cristina Cacciamali e Maria de Fátima Silva (2003), essa transformação no mercado de trabalho refletia os efeitos perversos da opção política neoliberal, expressada pelas maiores taxas de desemprego, de longa e curta duração, pela insegurança nas relações de trabalho, pelo rebaixamento salarial e pelo processo de informalização. A média da taxa de desemprego aberto na América Latina durante a década de 1990 foi de 8,7\%, com oscilações para cima e para baixo durante todo o decênio, como aponta o gráfico 1. 


\section{Gráfico 1 \\ Taxa de desemprego aberto na América Latina/ 1990-1999}

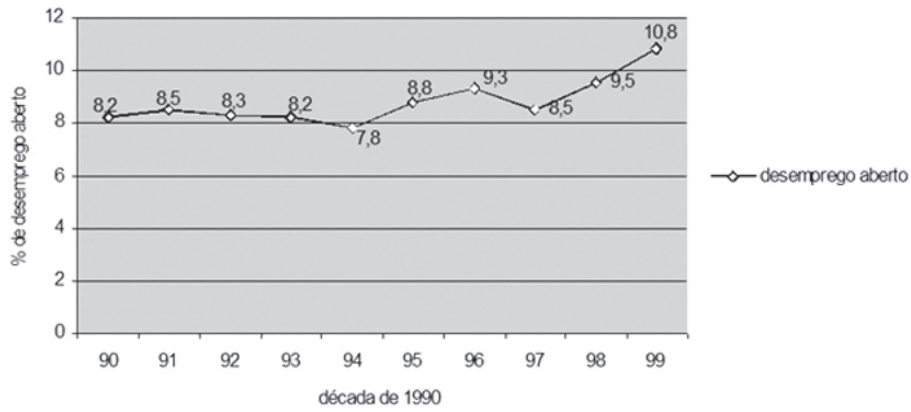

Fonte: Elaboração própria a partir de dados do Panorama Laboral/OIT 2000.

O crescimento da taxa de desemprego, ainda que com algumas quedas durante o decênio, evidencia a pressão das reformas econômicas, impactando diretamente no mercado de trabalho. Ao final dos anos 1990 quase $11 \%$ dos trabalhadores latino-americanos estavam desempregados.

E foram os grupos de renda mais baixa que sentiram os efeitos das reformas neoliberais com mais intensidade. Observando a taxa de desemprego entre os estratos de renda da população latino-americana, por quintis, podemos identificar que entre os mais pobres houve maior taxa de desemprego durante do decênio de 1990, como apresenta o gráfico 2.

\section{Gráfico 2}

Taxa de desemprego por quintil de renda na América Latina/ 1990-1999

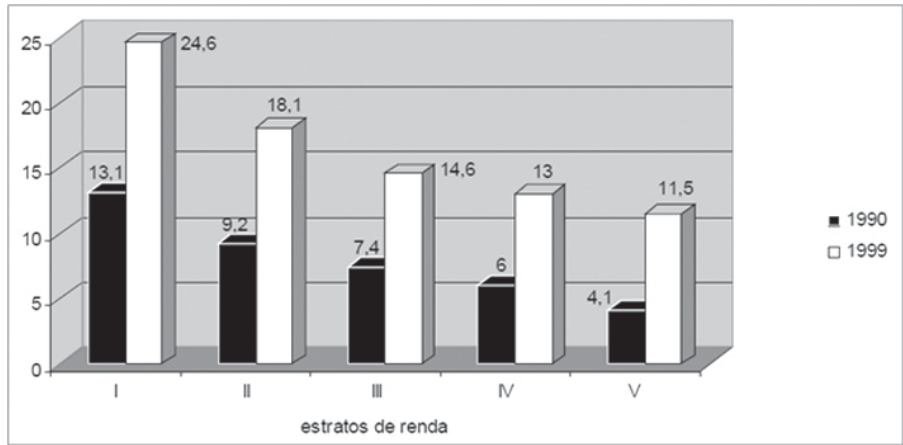

Fonte: Elaboração própria a partir de dados do Panorama Laboral/OIT 2000. 
Os dados são mais uma evidência da grande desigualdade entre ricos e pobres na América Latina, mas também uma demonstração de que as consequências das políticas neoliberais, atingiram, em graus variados, todos os estratos de renda. Ao final da década de 1990 as taxas de desemprego nos estratos praticamente duplicaram em relação ao começo do decênio estudado, como pode ser observado no gráfico 2. Mas ainda o peso maior recaiu sobre a população mais pobre. A porcentagem de desempregados no primeiro quintil chegou a $24,6 \%$. No segundo quintil essa taxa duplicou, ou seja, $18,1 \%$ das pessoas que compunham este estrato de renda estavam desempregadas. No terceiro quintil $14,6 \%$ das pessoas estavam sem emprego. No quarto quintil registrou-se uma taxa de 13\% de desempregados e, por fim, no quinto quintil a taxa de desemprego quase triplicou $(11,5 \%)$.

O crescimento do desemprego pode ser observado também na diferença entre a taxa de participação e de ocupação da População Economicamente Ativa (PEA) em 1990 e 1999, confirmando que o crescimento do mercado de trabalho foi insuficiente para absorver a população apta a trabalhar. Em 1990, 55,6\% da população na América Latina participava da PEA. Em 1999 já eram 59,4\%, ao passo que a taxa de ocupados se manteve praticamente inalterada entre o começo e o fim do decênio, permanecendo em cerca de $50 \%$. E desses ocupados, a maioria se encontrava no setor informal.

No Brasil, o Instituto Brasileiro de Geografia e Estatística (IBGE) diferencia o setor formal do informal pela organização da produção e não pela ilegalidade. O setor formal da economia é então o locus de acumulação de capital e de grandes inovações de caráter tecnológico, onde se tem a figura do trabalhador padrão: o assalariado com carteira assinada e proteção social. Já o setor informal se divide em dois grandes grupos. 1) formas de organização mercantis simples sem assalariamento permanente: trabalhadores por conta própria subordinados, os pequenos vendedores de serviços, as empresas familiares e o serviço doméstico. Ainda dentro dessa forma de inserção no mercado informal, é importante ressaltar que no interior da categoria vendedores de serviços estariam os indivíduos autônomos, como os engraxates, biscateiros, vendedores ambulantes/ camelôs que, ao contrário dos trabalhadores por conta própria subordinados, não estão submetidos a um só capital e não dispõem em geral de bons equipamentos de trabalho e nem de reserva de mercado. 2) quase empresas capitalistas: utilizam trabalho assalariado de forma permanente, mas não se enquadram como empresas tipicamente capitalistas porque seus proprietários participam da execução das atividades de produção e também por não ser a taxa de lucro a variável mais importante de seu funcionamento. Neste grupo há empresas com equipamentos e instalações próprios e estão em atividades em que há facilidade de entrada no mercado. Nas atividades informais estão ocupados tanto trabalhadores com habilidades e qualificação quanto trabalhadores desqualificados com renda muito baixa para o padrão social mínimo de vida. 
Polis, Revista Latinoamericana, $N^{\circ}$ 47, 2017

De acordo com relatório da Comissão Econômica para América Latina e o Caribe (CEPAL, 2000), de cada 20 milhões de empregos criados na década de 1990, 18 milhões correspondiam ao setor informal. Dentro deste setor, eram as microempresas as que mais empregavam. Os dados de Klein e Tokman, (apud Gurrieri e Sáinz, 2003) corroboram o relatório da CEPAL. Segundo os autores, de dez empregos criados entre 1990 e 1999 nove eram do setor de serviços, e destes $70 \%$ em atividades de baixa produtividade. A estrutura do emprego urbano na América Latina concentrou-se no setor informal, que durante a década de 1990 apresentou crescimento, como pode ser verificado no quadro 1.

\section{Quadro 1.}

\section{Estrutura do emprego urbano latino-americano anos 1990/1995/1999}

\begin{tabular}{|c|c|c|c|c|c|c|c|}
\cline { 2 - 8 } \multicolumn{1}{c|}{} & \multicolumn{4}{c|}{ Setor Informal } & \multicolumn{3}{c|}{ Setor Formal } \\
\hline Ano & Total & Trab. Indep. & Doméstico & Microempresa & Total & Setor público & Setor privado \\
\hline 1990 & $\mathbf{5 1 . 2}$ & 25.9 & 5.8 & 19.5 & $\mathbf{4 8 , 8}$ & 17.3 & 31.5 \\
\hline 1995 & 52.9 & 27.4 & 7.9 & 17.6 & 47.1 & 15.4 & 31.7 \\
\hline 1999 & $\mathbf{5 3 . 4}$ & 28.1 & 6.7 & 18.6 & $\mathbf{4 6 . 6}$ & 15.2 & 31.6 \\
\hline
\end{tabular}

Fonte: Elaboração própria a partir de dados da CEPAL/2000.

No começo da década de 1990, 51,2\% dos empregos urbanos latinoamericanos concentravam-se no setor informal. E destes, 25,9\% estavam em trabalho independente, ou o chamado por conta própria, que se caracterizava, segundo a CEPAL, por serviços de baixas qualidade e remuneração; como vendedores ambulantes e prestadores de serviços. 5.8\% eram trabalhos domésticos realizados em sua essência por mulheres e 19,5\% empregos em microempresa. Ao final da década a informalidade laboral continuava apresentando crescimento. Cerca de 53\% dos trabalhadores latino-americanos eram informais, distribuídos em trabalho independente (28,1\%), doméstico (6,7\%) e em microempresas (18,6\%).

Em contrapartida, o setor formal comportava, no começo dos anos 1990, 48,8\% dos trabalhadores latino-americanos, que se concentravam em empregos públicos (17,3\%) e em empresas privadas (31,5\%). Ao final do decênio, a taxa de emprego formal apresentava uma queda de 2,2 pontos percentuais (46,6\%). Dados que corroboram a afirmação de Cacciamali e Silva (2003), de que as reformas das legislações trabalhistas ocorridas nos países latino-americanos, especialmente na década de 1990, compuseram e reforçaram a política macroeconômica neoliberal repercutindo no mercado de trabalho, por meio de trabalhadores contratados sem registro, a expansão 
do trabalho por conta própria e a extensão de ocupação em pequenos negócios e no comércio de rua.

A precariedade do emprego é outra consequência marcante das políticas econômicas neoliberais e pode ser medida através de vários indicadores como remuneração, horas de trabalho, estrato produtivo/anos de estudo, seguridade social. O salário mínimo é um forte indicativo dessa precariedade e durante a década de 1990 manteve-se em torno de 30\% menor do que o valor de referência, que são cem dólares americanos, padrão estipulado por organismos internacionais como a CEPAL e a Organização Internacional do Trabalho (OIT). Outro fator de precariedade intensificado com as políticas neoliberais foi o aumento de trabalhadores com uma maior escolaridade no setor informal. Houve um aumento da porcentagem de trabalhadores, com seis a nove anos de estudo, comparando 1990 (36,9\%) e 1999 (46,4\%); e também na faixa de mais de 10 anos, na qual no início do decênio havia 19,9\% de trabalhadores com essa escolaridade empregados em trabalhos informais e em 1999 já eram 25,6\%. Estes dados refletem a precariedade no trabalho na medida em que pessoas qualificadas não são inseridas no mercado de trabalho formal e são, de um jeito ou de outro, absorvidas pelo mercado informal.

Essa absorção pode ser ainda mais precária no momento em que o emprego também é escasso no setor informal e por isso as horas trabalhadas tendem a diminuir, obrigando o trabalhador a fazer bicos para complementar o salário. E salário baixo é um fator de peso na previdência social, evidenciando dificuldade e até mesmo impossibilidade de pagá-la. O quadro 2 apresenta a porcentagem de trabalhadores com algum tipo de cobertura previdenciária na década de 1990.

\section{Quadro 2. \\ Mercado de trabalho por cobertura da previdência social na América Latina anos 1990 -1999}

\begin{tabular}{|c|r|r|r|r|r|r|}
\hline \multirow{2}{*}{$\begin{array}{c}\text { Mercado de } \\
\text { trabalho }\end{array}$} & \multicolumn{5}{|c|}{ \% de trabalhadores - previdência social } \\
\cline { 2 - 8 } & \multicolumn{3}{|c|}{1990} & \multicolumn{3}{c|}{1999} \\
\cline { 2 - 8 } & sim & não & ñ declarou & sim & não & ñ declarou \\
\cline { 2 - 8 } & & & & & & \\
\hline Formal & 75.2 & $\mathbf{2 4 . 6}$ & 0.2 & 67.2 & $\mathbf{3 2 . 6}$ & 0.2 \\
\hline Informal & 19.7 & $\mathbf{7 7 . 3}$ & 3.0 & 16.6 & $\mathbf{8 1 . 0}$ & 2.4 \\
\hline
\end{tabular}

Fonte: Elaboração própria a partir de dados do Panorama Laboral da OIT/2000 
No quadro 2 pode-se observar uma realidade muito comum na América Latina, que se intensificou durante os anos 1990 - a falta de previdência ao trabalhador latino-americano, evidenciando mais um fator de precarização do trabalho por dois motivos: não ter o benefício ou perdê-lo. Com relação aos formais, que geralmente têm o benefício fornecido pelas empresas que trabalham, sejam públicas ou privadas, houve uma queda de $8.1 \%$ entre os anos 1990(75,2\%) e 1999 (67,1\%). Isso devido à flexibilização trabalhista que retirou dos trabalhadores muitos direitos, entre eles o da proteção social. Quanto aos trabalhadores informais, a previdência social sempre foi benefício de uma minoria que podia pagar por ele. Ente 1990 (19,7\%) e 1999 $(16,6 \%)$ caiu a porcentagem de contribuintes. Muito desse decréscimo deveu-se à queda do poder aquisitivo do salário. Ao final da década de 1990, 81\% dos trabalhadores no setor informal não eram assegurados por nenhum tipo de sistema de previdenciário.

O cenário apresentado através dos dados sobre trabalho evidenciou aumento do desemprego, da informalidade e consequente precarização do trabalho nos anos 1990. Características que retroalimentaram a pobreza e a tornaram ainda mais profunda e extensa no decênio estudado.

Na América Latina a pobreza é um fenômeno social antigo, porém as transformações do capitalismo no final do século XX a intensificaram. As políticas econômicas de cunho neoliberal, implementadas de forma abrupta, em um curto período de tempo e num espaço marcado pela desigualdade, resultaram em mais pobreza contrariando o consenso dos organismos internacionais de que as reformas econômicas juntamente com a globalização trariam mais emprego e reduziriam a pobreza na região.

Nos países latino-americanos durante toda a década de 1990 foi possível visualizar duas importantes características da pobreza, analisandoa como uma questão de rendimento: 1) extensão, ou seja, a quantidade de pobres existente como proporção total da população e 2) intensidade: distância que separa a renda domiciliar per capita média dos indivíduos pobres do valor da linha da pobreza, medida em termos da porcentagem do valor dessa linha. Os dados referentes a essas duas características são relativos à linha de pobreza utilizada pela CEPAL, que representa uma quantidade mínima de renda que permite a um domicílio - em um determinado tempo e local - dispor de recursos suficientes que satisfaçam todas as necessidades de seus membros. (Mattei, 2012, p.6)

A primeira característica pode ser observada através da evolução da pobreza na região, evidenciada pelo crescimento do número de pobres e indigentes, principalmente na década de 1990. O gráfico 3 apresenta essa evolução e os dados apontam o motivo pelo qual a pobreza tornou-se uma grande preocupação social. 


\section{Gráfico 3 \\ Evolução \% da pobreza e da indigência na América Latina - 1980/1986/ 1990/1994/1997/1999}

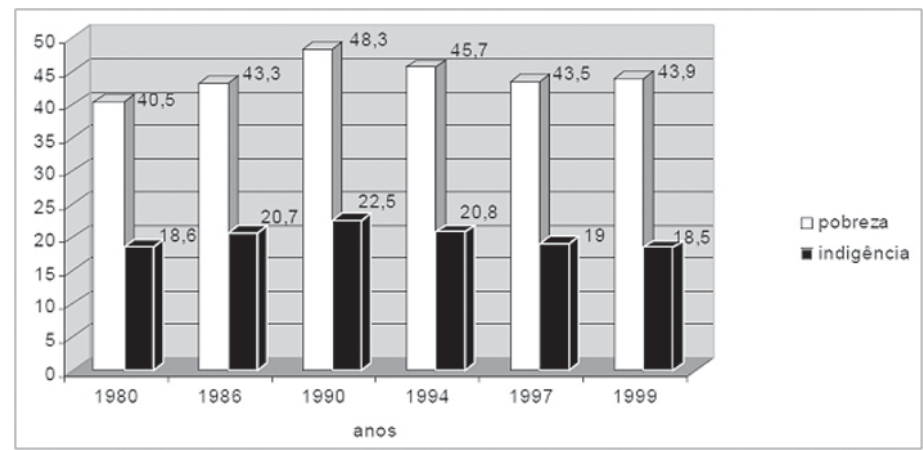

Fonte: Elaboração própria a partir de dados estatísticos da CEPAL (2000) www.cepal.org

Os dados apresentam grande porcentagem de pobres na América Latina entre as décadas de 1980 e 1999, atingindo mais de 40\% da população latino-americana durante estes dois decênios. Percentualmente, 1990 foi o ano com maior extensão da pobreza e da indigência, registrando 48,3\% e 22,5\% respectivamente. A partir de 1994 os percentuais de pobreza caíram, registrando naquele ano uma taxa de 45,7\%, em 1997 43,5\% e finalizando a década com $43,9 \%$ da população latino-americana sob o estigma da pobreza. Porém os números absolutos refletem uma constante ascensão do número de pobres entre os anos de 1980 e 1999. Segundo dados da CEPAL, em 1980 havia 135 milhões de pobres, em 1990 chegou-se ao patamar dos 200 milhões e em 1999 foram registradas 211 milhões de pessoas vivendo em situação de pobreza. Com relação à indigência, os números absolutos também cresceram. Em 1980, os 18,6\% de indigentes se traduziam em 62,4 milhões de pessoas. Em 1990 os 22,5\% representavam 93,4 milhões de latino-americanos e ao final de 1999 os 18,5\% de indigentes na região significavam 89,4 milhões de pessoas vivendo sob a situação de indigência.

A intensidade da pobreza, ou seja, o quão distante as pessoas em situação de pobreza estão do valor fixado como limiar de risco, é também um outro bom indicador para se visualizar a gravidade da situação dos pobres na América Latina. O gráfico 4 apresenta dados que evidenciam o crescimento dessa brecha entre a renda dos pobres e as linhas de pobreza e indigência na América Latina (mensuradas em dólar), no começo e ao final da década de 1990. 


\section{Gráfico 4 \\ Taxa de intensidade de pobreza e indigência (em renda dos pobres comparada à linha de pobreza) na América Latina - 1990/1999 \\ Valor da linha de pobreza: 1990 - \$66,00 1999- \$ 84,00 Valor da linha de indigência:1990 - \$33,00 1999- \$ 42,00}

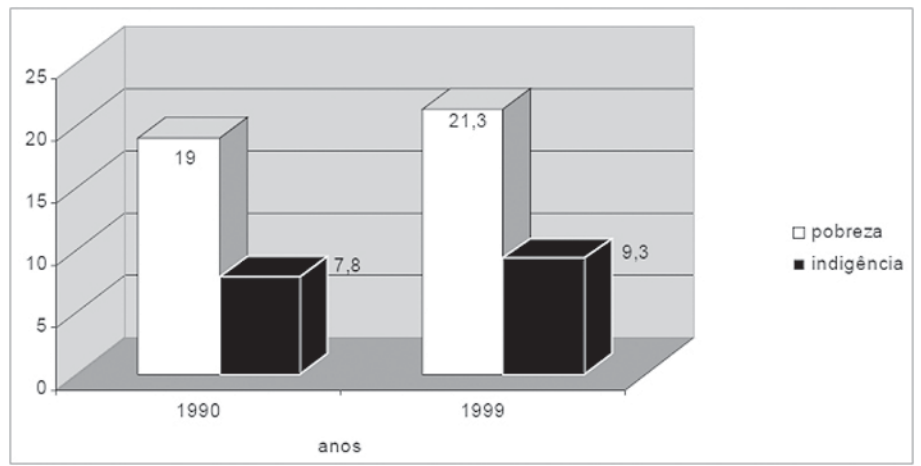

Fonte: Elaboração própria a partir de dados estatísticos da CEPAL (2000) www.cepal.org

O gráfico 4 ilustra a intensidade da pobreza na América Latina no período estudado. Em 1990, os 48\% de pobres latino-americanos estavam heterogeneamente distribuídos abaixo da linha da pobreza com uma renda média per capita 19\% abaixo do valor da linha de pobreza, que, no período, equivalia a 66 dólares, conforme mensuração da CEPAL. Em 1999 esse gap havia ampliado para 21,3\% demonstrando uma distância ainda maior no déficit de renda dos pobres com relação ao valor da linha de pobreza, mensurada em 84 dólares. Em 1990, a renda das pessoas em situação de indigência era 7,8\% menor do que a linha de indigência proposta pela CEPAL. Ao final do decênio a amplitude era maior, registrando 9,3\% abaixo do valor estipulado pela instituição referida, 42 dólares.

O quadro 3 apresenta um panorama da incidência da pobreza em algumas categorias profissionais durante a década de 1990. 


\section{Quadro 3. \\ Incidência da pobreza, em porcentagem, em algumas categorias profissionais na América Latina em 1990/1994/1997/1999}

\begin{tabular}{|c|c|c|c|c|c|c|}
\hline \multirow[t]{2}{*}{ Ano } & \multirow{2}{*}{$\begin{array}{c}\% \\
\text { Assalariados } \\
\text { pobres } \\
\text { setor } \\
\text { público }\end{array}$} & \multicolumn{3}{|c|}{$\begin{array}{c}\text { \% Assalariados pobres do setor privado } \\
\text { (não profissionais e não técnicos) }\end{array}$} & \multicolumn{2}{|c|}{$\begin{array}{c}\text { \% Trab. pobres por conta } \\
\text { própria/ } \\
\text { não qualificados }\end{array}$} \\
\hline & & $\begin{array}{l}\text { Emp. médio } \\
\text { porte }\end{array}$ & $\begin{array}{l}\text { Micro } \\
\text { Empresa }\end{array}$ & $\begin{array}{l}\text { Empregado } \\
\text { doméstico }\end{array}$ & $\begin{array}{l}\text { Indústria } \\
\text { construção }\end{array}$ & $\begin{array}{l}\text { Comércio } \\
\text { serviços }\end{array}$ \\
\hline 1990 & 21.7 & 33.7 & 40.9 & 35.5 & 39.0 & 33.6 \\
\hline 1994 & 20.1 & 27.7 & 38.9 & 32.8 & 36.2 & 29.5 \\
\hline 1997 & 18.4 & 28.0 & 36.4 & 32.6 & 34.4 & 29.6 \\
\hline 1999 & 16.0 & 27.9 & 41.0 & 31.0 & 36.0 & 30.6 \\
\hline
\end{tabular}

Fonte: Elaboração própria a partir de dados do Panorama Social da América Latina

CEPAL / 2000-01

O quadro 3 evidencia que no serviço público a porcentagem de pobres diminuiu durante os anos 1990, mas o número de empregos públicos também sofreu retração devido às privatizações. A média de trabalhadores pobres neste setor ficou em torno de 19\% durante do decênio. Quanto aos assalariados do setor privado, nas três categorias apresentadas, a pobreza teve maior incidência em trabalhadores de microempresa, com uma média de 39,3\%, durante a década de 1990. 29\% dos trabalhadores de empresas de médio porte foram considerados pobres no mesmo período e $33 \%$ de empregados domésticos foram classificados em situação de pobreza. A percentagem de pobres, durante a década, também foi elevada entre os trabalhadores autônomos, tanto da construção civil (36,4\%) como do setor de comércio e serviços (31\%).

Os dados mostram a incidência da pobreza nas diversas categorias de trabalhadores, desmistificando a ideia de que o trabalho por si retira as pessoas dessa condição. Estas informações sugerem que o estudo do trabalho, para melhor compreendê-lo como um fator de diminuição da pobreza, deve partir de elementos como salários dignos, respeito a horas de trabalho e qualificação do trabalhador, entre outros.

\section{A estatística verificando relações: reforma econômica, desemprego e pobreza}

Com a estatística descritiva apresentamos o perfil do trabalho e da pobreza na América Latina, nos anos 1990, sugerindo uma relação com as 
reformas econômicas, implementadas no mesmo período, já que o aumento dos problemas sociais foi atribuído em grande parte às orientações econômicas de caráter neoliberal seguidas pelos governos latino-americanos, durante todo o decênio. Os dados do quadro 4 apontam nessa direção ao evidenciarem a evolução das reformas, juntamente com o crescimento do índice de desemprego e do número de pobres.

\section{Quadro 4. \\ Evolução das reformas econômicas, desemprego e pobreza na América Latina/ anos 1990}

\begin{tabular}{|c|c|c|c|c|c|c|c|c|c|c|}
\hline Indice -taxa & 1990 & 1991 & 1992 & 1993 & 1994 & 1995 & 1996 & 1997 & 1998 & 1999 \\
\hline $\begin{array}{l}\text { Reforma } \\
\text { econômica }\end{array}$ & 0.72 & 0.74 & 0.76 & 0.77 & 0.78 & 0.79 & 0.81 & 0.82 & 0.82 & 0.82 \\
\hline Desemprego & 5.8 & 7.5 & 8.1 & 8.2 & 8.3 & 10 & 9.9 & 9.3 & 10.3 & 11.0 \\
\hline Pobreza* & 200 & 200.96 & 202.58 & 204 & 205.97 & 207.30 & 208.54 & 209.23 & 210.34 & 211 \\
\hline
\end{tabular}

Fonte: Elaboração própria a partir de dados da CEPAL (2000) e PNUD (2004)

* Pobreza foi observada a partir do valor absoluto de pobres na América Latina, em milhões.

O índice de reforma econômica da América Latina para a década de 1990, desenvolvido pela CEPAL, evidencia a evolução das reformas na região. Este índice foi elaborado a partir de cinco componentes: políticas de comércio internacional, políticas impositivas, políticas financeiras, privatizações e contas de capitais, e varia de 0 a 1 . O zero indica a falta de reformas e um a completa aplicação das orientações neoliberais. Os dados demonstram que a região latino-americana concretizou muitas orientações do Consenso de Washington. Em 1990, já se registrava um índice de 0,72. Ao final da década o índice era de 0,82. Paralelamente, o desemprego e a pobreza também aumentaram sugerindo uma relação de causa-efeito entre a reforma e estes indicadores sociais. Para se verificar esta possível relação e sua significância utilizou-se o modelo de regressão linear simples ${ }^{4}$, rodado no programa estatístico PASW18 ${ }^{5}$ (Predictive Analytics Software). Com relação ao modelo de regressão linear foram observados todos os pressupostos. Foram analisados três aspectos: 1) o quanto a variação da variável independente explica a variação da variável dependente; 2) a significância desse movimento e 3) a estimação da equação de regressão, que prevê o valor da variável resposta (desemprego e pobreza) a partir do valor da variável explicativa (reforma econômica). 
Verificou-se tanto a relação entre reforma econômica (variável explicativa) e desemprego (variável resposta) como entre reforma econômica e pobreza (variável resposta). E constatou-se que os aumentos do desemprego e da pobreza na América Latina podem ser explicados pelo aumento das reformas econômicas. A seguir, são apresentadas algumas estatísticas importantes que comprovam a relação.

A primeira estatística de interesse, no modelo de regressão, é o coeficiente de determinação $\left(\mathrm{R}^{2}\right)$, que é uma medida de aderência dos dados em torno da reta de regressão e é usualmente interpretada como a proporção da variância na variável dependente explicada pela variação das variáveis independentes (Figueiredo Filho et al., 2011). A estatística apontou que 85\% da variação do desemprego pode ser explicada pela variação da reforma econômica. Além disso, a associação entre as variáveis é positiva. Ou seja, à medida que aumenta o índice de reforma eleva-se a taxa de desemprego. O gráfico 5 evidencia a distribuição positiva em torno da reta.

\section{Gráfico 5 \\ Dispersão das variáveis reforma econômica e desemprego}

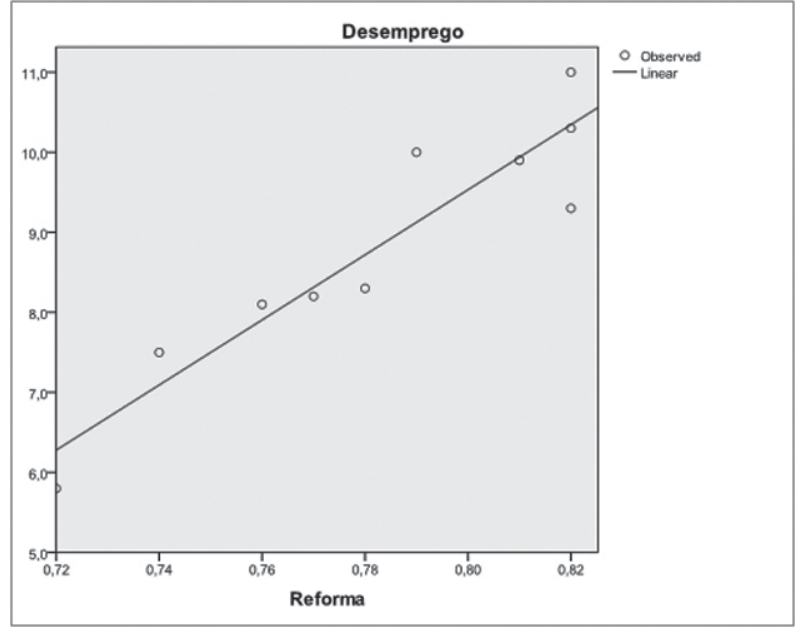

Fonte: Elaboração própria a partir de dados da CEPAL (2000) e PNUD (2004)

Este mesmo comportamento pode ser verificado na relação entre reforma econômica e pobreza. A estatística aponta que 95\% da variação do aumento da pobreza pode ser explicada pela variação do aumento da reforma econômica. A distribuição dos pontos em torno da reta no gráfico 6 evidencia que a relação é diretamente proporcional, além de ser forte. 


\section{Gráfico 6 \\ Dispersão das variáveis reforma econômica e pobreza}

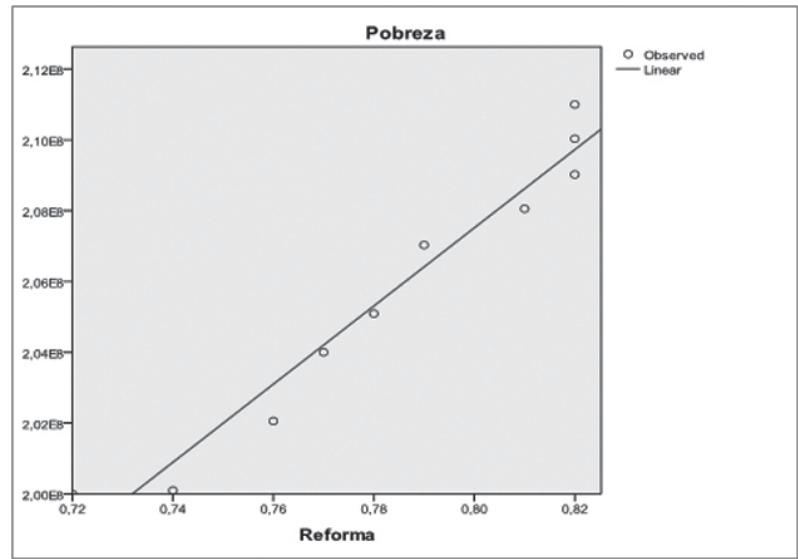

Fonte: Elaboração própria a partir de dados da CEPAL (2000 e PNUD (2004)

Outra estatística importante é a análise de variância (ANOVA), que testa a significância da regressão, estudando o comportando das variações no modelo. Esta análise apresenta como ponto principal o teste F; que tem como objetivo verificar se há ou não regressão linear entre as variáveis e a significância do modelo através do p-valor. O teste $\mathrm{F}(51,8)$ foi significativo a $\mathrm{p}=0.000$ para a análise entre reforma econômica e desemprego. $\mathrm{O}$ teste $\mathrm{F}$ $(172,4)$ também apresentou significância a $\mathrm{p}=0.000$ para reforma econômica e pobreza.

Por fim, a análise dos coeficientes de regressão estimados que permitem a elaboração do modelo probabilístico. Interessante, neste caso, observar o coeficiente associado à variável independente, representado pelo símbolo $\beta$, coeficiente $\alpha$ referente à constante do modelo, e a relação teoricamente esperada. Para a relação reforma econômica e desemprego os coeficientes de regressão estimados foram de $\beta=40,6$ e $\alpha=-22,9$. O valor positivo do coeficiente $\beta$ é mais uma evidência da relação diretamente proporcional e confirmação da hipótese. Ou seja, quanto maior o índice de reforma econômica maior será o índice de desemprego. E o valor de $\beta$ indica que o desemprego aumenta 40,6 pontos para cada ponto de aumento no índice de reforma econômica.

Para a relação reforma econômica e pobreza os coeficientes de regressão estimados foram de $\beta=1,104 \mathrm{E} 8$ e $\alpha=1,192 \mathrm{E} 8$. O sinal positivo de $\beta$ também indica que o coeficiente apresenta a direção teoricamente esperada de que o aumento de reforma econômica acarreta em aumento no número de 
pobres. Substituindo estes dados na equação de regressão é possível estimar os índices de desemprego e pobreza.

Equação de previsão para as variáveis reforma econômica e desemprego

$$
\begin{gathered}
y=\alpha+\beta x \\
y=-22,9+40,6(0,82) \\
y=10,39
\end{gathered}
$$

Equação de previsão para as variáveis reforma econômica e pobreza

$$
\begin{aligned}
& y=\alpha+\beta x \\
& y=1,192+1,104 \mathrm{E} 8(0,82) \\
& y=2,097 \mathrm{E} 11
\end{aligned}
$$

Onde:

y = variável dependente

$\alpha=$ coeficiente da constante- valor esperado da variável dependente quando todas as variáveis independentes assumem valor igual a zero

$\beta=$ coeficiente da variável explicativa associada ao evento

$\mathrm{x}=$ variável independente

Os resultados preditos nas equações se aproximam dos resultados observados, demonstrando a influência e a causalidade da variável independente na variação das variáveis dependentes. Conforme a equação de regressão, o desemprego no ano de 1999 sob um índice de reforma econômica de 0.82 seria de em média 10,39\%, conforme o modelo. Conforme dados da CEPAL, o desemprego no referido ano foi de 11\% para a variável pobreza também verifica-se essa tendência. Segundo a equação, com um índice de reforma econômica de 0.82 haveria uma média de 209 milhões de pobres na América Latina em 1999. De acordo com a CEPAL, no referido ano foram registrados 211 milhões de pobres na região.

\section{Algumas Considerações}

Em suas reflexões sobre o neoliberalismo na América Latina, David Ibarra (2011, p. 240) observa que "acomodação neoliberal alterou a ordem interna dos países", alterando a distribuição de ingressos, as oportunidades de progresso, as metas de geração de emprego, e alargando a distância entre pobres e ricos. Segundo o autor, são escassos os avanços em corrigir a desigualdade e a pobreza se torna endêmica. 
Essas constatações normativas de Ibarra vão ao encontro das constatações empíricas deste estudo, apresentadas através das estatísticas descritiva e inferencial. No que se refere ao mundo do trabalho, pode-se observar, a partir dos dados apresentados, que o número de postos de trabalho na América Latina, durante o período neoliberal, diminuiu, os empregos tornaram-se mais precários e informais. E a pobreza, que não é um fenômeno social novo na região, expandiu-se com rapidez naquele decênio de 1990. Razão pela qual os resultados deste artigo dão consistência ao argumento de que a pobreza é um fenômeno produzido e reproduzido por relações humanas em um determinado espaço e tempo.

Os dados também nos permitiram verificar uma relação simétrica entre as reformas econômicas neoliberais e desemprego e pobreza; de modo que podemos afirmar que os aumentos do desemprego e da pobreza na América Latina, na década de 1990, estão fortemente relacionados à implementação de políticas econômicas neoliberais. O modelo de regressão apresentou a causalidade. E esta relação, diretamente proporcional, mostrouse bastante visível, através da abertura comercial, entrada de investimentos estrangeiros na região, privatizações, disciplina fiscal, ao mesmo tempo em que as taxas de desemprego/subemprego e pobreza aumentavam, colocando em evidência a fragilidade social dessas reformas.

Nesse sentido, ceder à utopia neoliberal trouxe a uma boa parte da população latino-americana desemprego e pobreza. O fosso social, resultante dessas políticas, estendeu e intensificou-se. A virada ao século XXI ficou marcada na América Latina pelo contingente de desempregados e pobres, advindos, em boa parte, do ajuste estrutural. Nessa direção, evidenciar as consequências é um modo de questionar e refletir sobre a implementação e o impacto de políticas que acarretam mínimo benefício à coletividade. 


\section{Notas}

${ }^{1}$ Esta investigação é parte de uma pesquisa que resultou em minha tese de doutorado em Ciência Política pela Universidade Federal do Rio Grande do Sul/Brasil - "Escolhas Políticas, Decisões Econômicas, Consequências Sociais - um estudo sobre os impactos da democracia procedimental e do neoliberalismo na América Latina e no Brasil”

${ }^{2}$ As políticas econômicas neoliberais foram reformas institucionais implementadas na América Latina entre o final dos anos 1980 e durante a década de 1990. Essas orientações foram elaboradas em meados dos anos 80, no Institute for Intenational Economics, de Washington, visando um novo crescimento econômico para a região, com base em 10 pontos. 1) incremento da poupança mediante uma forte disciplina fiscal; 2) reorientação do gasto público para programas sociais bem elaborados (focalização); 3)reforma do sistema tributário para ampliar a base impositiva; 4) consolidação da supervisão do Banco Central; 5) manutenção de tipo de câmbio competitivo; 6) liberalização do comércio intra-regional; 7) criação de uma economia de mercado altamente competitiva mediante privatização e liberalização de todos os mercados de bens e serviços, com especial ênfase na desregulação do mercado de trabalho; 8) garantia ao conjunto da sociedade os direitos de propriedade; 9) criação de um banco central autônomo, poder judiciário independente e incorruptível, e entidades que promovam a produtividade; 10) incremento do gasto público educativo no ensino primário e secundário.

${ }^{3}$ Privação ou negação do Estado em aplicar leis e ministrar a justiça.

${ }^{4} \mathrm{O}$ objetivo da análise de regressão é prever uma única variável dependente a partir do conhecimento de uma ou mais variáveis independentes. Quando o problema envolve uma única variável independente, a técnica estatística é chamada de regressão simples. (Hair et al, 2009, p. 154)

${ }^{5}$ É um software de análise estatística. 
Polis, Revista Latinoamericana, $N^{\circ}$ 47, 2017

\section{Bibliografia}

Antunes, R. e Alves, G. (2004). As mutações no mundo do trabalho na era da mundialização do capital. Educação Sociológica, 25 (87), 335351. Recuperado de https://www.nescon.medicina.ufmg.br/biblioteca/imagem/0184.pdf

Arriagada, C. (2000). Pobreza en América Latina: nuevos scenarios y desafios de politicas para el habitat urbano. Série medio ambiente e desarrollo. Santiago, Chile: CEPAL

Cacciamalli, M. C. (2000). Processo de informalidad y sector informal reexamen de una discusión. Revista Venezolana de Economia y Ciências Sociales, 6 (3) 95-110. Recuperado de http://www.ucv.ve/fileadmin/ user_upload/faces/problemas_sociales_contemporaneos/CESOC/ S E P T I E M B R E_D I C I E M B RE_ 3_ 2000 _ A J U S T E _ ESTRUCTURAL_Y_DESAJUSTES_SOCIALES.pdf

Idem (2003). A desfiliação do estatuto do trabalho na década de 1990 e a inserção dos ocupados que compõem as famílias de menor renda relativa. In: Chahad, J.P (org.) Mercado de trabalho no Brasil padrões de comportamento e transformações institucionais (pp. 247284) São Paulo, Brasil: LTr.

Castel, R (1998). As metamorfoses da questão social: uma crônica do salário. Petrópolis, Brasil: Vozes

Idem (2010). As transformações da questão social. In: Castel, R, Wanderley, L. y Belfiore M. (orgs.) Desigualdade e questão social (pp. 21-54). São Paulo, Brasil: Educ

Castells, M. (1999). A era da informação: economia, sociedade e cultura. São Paulo, Brasil: Paz e Terra

CEPAL, (2000).Panorama Social da América Latina. Santiago, Chile.

Figueiredo Filho, D., Nunes, F., Rocha, E., Santos, M., Batista, M., Silva Junior, A. O que fazer e o que não fazer com a regresssão: pressupostos e aplicações do modelo linear de mínimos quadrados ordinários (MQO). Revista Política Hoje, 20 (1), 44-99.

Gurrieri, A. e Sáinz, P (2003). Empleo y movilidad estructural. Trajectoria de um tema prebischiano. Revista De La Cepal, 80, 141-164. Recuperado de: http://archivo.cepal.org/pdfs/revistaCepal/Sp/ 080141164.pdf

Gutiérrez, A. (2007). Pobre’, Como Siempre ... - Estratégias de reproducción social en la pobreza - um estudio de caso. Córdoba, España: Ferreyra Editor. 
Hair, J., Black, W., Babin, B., Anderson, R., y Tatham, R. (2009). Análise multivariada de dados. Porto Alegre, Brasil: Bookman.

Harvey, D. (1992). Condição pós-moderna. São Paulo, Brasil: Loyola.

Ibarra, D. (2011). O neoliberalismo na América Latina. Revista de Economia Política, 31, 2 (122) 238-248. Recuperado de: http://www.scielo.br/ pdf/rep/v31n2/04.pdf

Leguizamón, S. (2005). Trabajo y produción de la pobreza en lationoamérica y el Caribe: discursos, estructuras y actores. Buenos Aires, Argentina: Clacso Crop.

Mattei, L. (2012). Pobreza na América Latina: diferenças intra-regionais e principais tendências. Revista Pesquisa \& Debate. 231 (41) 01-24. Recuperado de: https://revistas.pucsp.br/index.php/rpe/article/view/ $12399 / 8985$

Narayan, D. (2000). Bonds and bridges: social capital and poverty. Washington DC, EE.UU: World Bank.

Oyen, E. (2002). Produción de la pobreza: Un enfoque diferente para compreender a pobreza. Centre For International Poverty Research Crop, Bergen.

Organização Internacional do Trabalho (2000). Panorama Laboral de América Latina y el Caribe. Lima, Perú: OIT

Programa das Nações Unidas para o Desenvolvimento (2004). Democracia na América Latina. São Paulo, Brasil

Rahnema, M. (2005). Erradicating poverty or the poor? Recuperado de: http//:www.iucn.org/themes/ceesp 